\title{
Biomass Allocation and Root Characteristics of Early-Stage Poplars (Populus spp.) for Assessing Their Water-Deficit Response During SRC Establishment
}

\author{
Matthias Meyer $^{1}$ (D) $\cdot$ Kristin Morgenstern $^{1}$ (D) Dávid Heilig ${ }^{2}$ (D) $\cdot$ Bálint Heil $^{2,3} \cdot$ Gábor Kovács $^{2,3} \cdot$ Christoph Leibing $^{4} \cdot$ \\ Doris Krabel ${ }^{1}$ (iD
}

Received: 7 July 2020 / Accepted: 25 February 2021 / Published online: 17 April 2021

(C) The Author(s) 2021

\begin{abstract}
Early above- and belowground biomass fractionation, root diameter composition and allocation of cumulated fine root length per total leaf area of Populus clones have been measured for a pre-assessment of the risk for plantation establishment during spring drought conditions. Four clones of Populus $\times$ euramericana, and one P. nigra $\times$ P. maximowiczii clone (cv. Max 3 ), were planted in sandy mix substrate and were exposed to one normal and one deficit watering regime over 65-day greenhouse experiments conducted during early summer. The $P . \times$ euramericana hybrids showed plasticity of their root biomass fractions. Although clone Max 3 was among the productive clones, even under deficit watering, it was not able to respond plastically to deficit watering. It showed no increase in the root biomass fraction and no increase in the ratio of cumulated fine root length per total leaf area. Therefore, the clone Max 3 should not be planted under high risk for spring drought. Planting the investigated $P$. $\times$ euramericana clones under water deficit likely involves a lower risk, but clone differences within this group must be considered. It can be concluded that the water deficit response of biomass allocation to roots and of the ratio of fine root length per unit leaf area is suitable traits to improve drought risk assessments that are based on yield response of poplar clones to drought. Percent plant loss data and the yield at the end of the first SRC rotation will be suitable to verify the present greenhouse assessment.
\end{abstract}

Keywords Short rotation coppice · Bio-economy · Plantation establishment · Water deficit · Spring drought · Sandy soil · Fine root $\cdot$ Hybrid poplar $\cdot$ Black poplar $\cdot$ Balsam poplar

\section{Introduction}

The taxonomic sections of the black poplars (Populus spp., sect. Aigeiros) and of the balsam poplars (sect. Tacamahaca) are of particular importance for commercial use of poplar

Matthias Meyer

matthias.meyer@tu-dresden.de; https://tu-dresden.de/bu/umwelt/ forst/forstbotanik/forstbotanik?set_language=en

1 Institute of Forest Botany and Forest Zoology, Molecular tree physiology group, TU Dresden, Pienner Str. 7, D-01737 Tharandt, Germany

2 Faculty of Forestry, Institute of Environmental and Earth Sciences, University of Sopron, P.O. Box 132, Sopron H-9400, Hungary

3 Ökoforestino Kft., Ibolya út 11. V/21, Sopron H-9400, Hungary

4 IKEA Industry Slovakia, Továrenská 2614/19, SK-901 01 Malacky, Slovakia crops for bio-economy because of their ease of hybridisation and vegetative propagation [1]. Because of the wide range of adaptation within and between the poplar species used for breeding [2-5], clone-specific differences in the response of young poplars to abiotic stresses such as drought or frost must be considered [6, 7]. For the establishment of largescale short rotation coppice (SRC) operations, the adaptation response of commercial clones in the early stage after planting should be known to avoid high plant losses and costly re-planting [8]. Marginal farmland with non-optimal water conditions on sandy soils constitutes a high risk of environmental stress and operational losses during SRC establishment. This process begins with planting rods into the rather dry, sandy soil and ends up with the successful development of a welldimensioned root system and aboveground plant parts. The biomass allocation to young plant compartments must be balanced to overcome water deficits and to allow recovery after possible summer droughts. The early root-to-shoot ratio and the capability to develop roots from poplar cuttings are under 
strong genetic control [9-12]. But little is known about the use of (fine) root traits in poplar breeding or clone selection [13, 14].

When comparing species of different biomes, it is widely accepted that wider, more intensive rooting indicates better adaptation to dry areas [15]. Accordingly, the long-term favouring of root development under water deficit at the expense of shoots and foliage, while reducing leaf area and productivity are well-known adaptations within the genus Populus (reviews in $[16,17])$. Beyond that, there is a change in carbon or biomass allocation to the water-absorbing and transpiring tissues. However, other studies on forest trees have shown different important causes of variation of the root-toshoot ratios of biomasses, e.g. tree size or age, species composition, temperature and $\mathrm{N}$ availability [18-20]. Moreover, the root-to-shoot biomass ratio cannot account for the waterdeficit adaptation process in plants, which remain their aboveand belowground biomass fractions relatively constant after drought impact while changing their root morphology towards finer roots [21]. Hence, the ratio of root surface area per leaf surface area or that of the root length produced per unit leaf area can be more functionally descriptive (reviews in [15, 21]). Unfortunately, non-destructive visualisation of the poplars' highly dynamic fine root growth under in situ conditions was not yet possible. Hence, greenhouse trials that adequately simulate different environments for potted trees in combination with destructive measurements are an appropriate means for investigating the early development of poplars [13]. To the best of our knowledge, there were no standardised pot trial designs for poplar clones grown under different water deficit conditions. Moreover, water utilisation and growth differences between tested clones may result in manifestation of different stress levels with regard to plant-available pot moisture. Pot trial designs that include water treatments can focus either on clone differences in genotypic stress sensitivity to common levels of soil moisture or on clone differences in growth and adaptation responses to a common watering amount. The first approach requires maintenance of a common level of soil moisture among all clones for each treatment and consequently, the clone-specific adaptation of the watering amounts in line with each clones' water consumption at the given moisture level. The other approach requires common amounts of supplemental irrigation water while potentially different belowground moisture stress levels between clones must be considered.

The present investigation was based on the general premise that the early-stage plants of different clones would be exposed to a common rainfall deficit after planting in a field during spring drought conditions. The decision was made for this study that the value of stress level was not as important as the value of growth result or potentially detrimental morphological adaptations of the roots or biomass allocation. Therefore, the present greenhouse trial followed the second approach. Common watering amounts were applied to all clones in normal watering (NW) and deficit watering (DW) treatments. The main objectives were (i) to assess the earlystage growth and biomass allocation responses of poplar plants to deficit watering and (ii) to detect differences in the diameter composition of the early root systems. Our focus was on a group of relatively new $P . \times$ euramericana clones, syn. $P . \times$ canadensis $(P$. deltoides $\times P$. nigra, intra-sectional Aigeiros hybrids) in comparison with a $P$. nigra $\times$ $P$. maximowiczii clone that is an inter-sectional hybrid (Aigeiros $\times$ Tacamahaca). $P . \times$ euramericana clones and intra- or inter-sectional poplar hybrids of the section Tacamahaca form the most important groups of commercial poplar hybrids available for SRC operations [22-30].

First, we hypothesised that the early biomass $(B M)$ allocation to roots, shoots and foliage differs between the present Aigeiros hybrids and the clone that comprises a parent of the section Tacamahaca. Beyond clone differences in BM allocation, a lack in plasticity of carbon allocation under water deficits was reported by other authors for an inter-sectional Tacamahaca $\times$ Aigeiros hybrid $(P$. trichocarpa $\times$ $P$. deltoides) in comparison with a $P . \times$ euramericana hybrid in a largescale plantation trial [31].

Second, we hypothesised that there were between clone differences in the root diameter composition and that different root diameter classes vary in their responses to deficit watering treatments. This was expected because it was known that Tacamahaca species and $P . \times$ euramericana or $P$. nigra clones can differ in (fine) root morphology and turnover and in the expansion of their root systems [14, 32-34]. Third, we hypothesised in line with the previous hypotheses that the present clones differ in their allocation response of cumulated fine root length per total leaf area. Clone-specific differences in the allocation characteristics of plantation poplars were successfully investigated by determining the ratio of fine roots $(<0.5 \mathrm{~mm})$ produced per unit leaf area [35].

The present study was linked with an operational SRC project. Clones should be identified that bear potential risks for SRC establishment during dry spring planting conditions on sandy soils. In addition, the suitability of the measured traits for the assessment of the poplar clones' responses to post-planting drought was discussed.

\section{Materials and Methods}

\section{Poplar Clones and Plant Containers}

The $P . \times$ euramericana poplar clones AF16, AF18, A4A and Vesten were subjected to a standardised early growth pot trial in a greenhouse, either in 2018 or 2019 (Table 1 and Supporting Information S1). In both years, the clone Max 3 was tested and served also as a between-year reference. Max 3 
Table 1 Poplar (Populus spp.) clones, $n=$ sample number of plants investigated in greenhouse trials. $d_{\text {cutting }}=$ mean upper cutting diameter at time of planting \pm standard error. The cutting length was generally $35 \mathrm{~cm} . N W$, normal watering; $D W$, deficit watering $[23,25,29,36]$

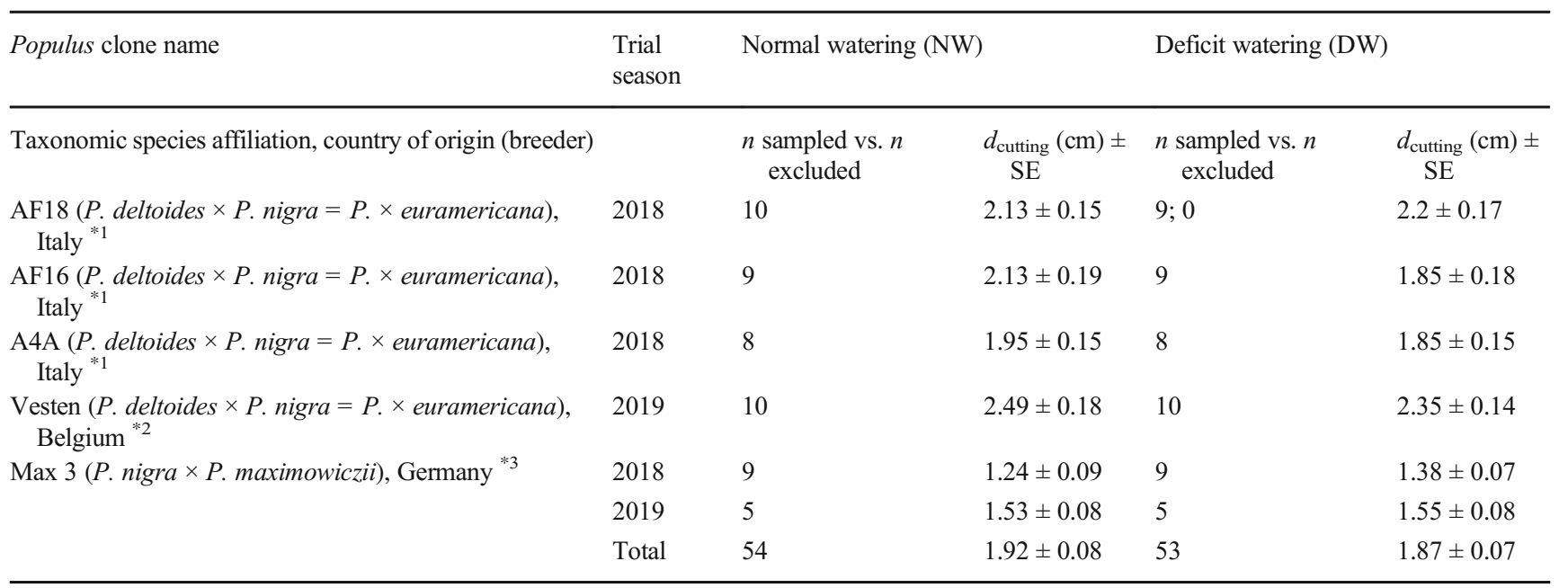

\footnotetext{
${ }^{* 1}$ Present-time contact of the breeder: Alasia New Clones Italy, Savigliano (CN), Italy; taxonomic information [11]

${ }^{*}$ Present-time contact of the breeder: INBO (Research Institute for Nature and Forest), Geraardsbergen, Belgium; taxonomic information: [11, 15]

${ }^{*}$ Present-time contact of the breeder: Northwest German Forest Research Institute (NW-FVA), Hannoversch Münden, Germany; taxonomic information $[17,40]$
}

is an inter-specific hybrid of the Populus sections Aigeiros $\times$ Tacamahaca $(P$. nigra $\times$ P. maximowiczii, [25], stool bed: Lignovis GmbH, Germany). The studied clones were selected because they have been used for large SRC operations that are aimed at providing dendromass for industrial value chains (Supporting Information S1). The $P . \times$ euramericana cuttings were obtained by excision from dormant 1.80-m-long rods, delivered by two European tree nurseries during late winter for operational spring planting. All cuttings were $35 \mathrm{~cm}$ long. The mean weight of the cuttings is presented in Table 1. All cuttings had an upper and a lower cross-sectional cut surface, none carried a terminal bud or an apical meristem. They were stored four to 6 weeks before planting at $2{ }^{\circ} \mathrm{C}$ in plastic bags to protect against desiccation. To maintain their condition comparable with that of field operations, they were not soaked in water. The correct genetic identity was verified.

All cuttings were planted into 3.691-L standardised sandy soil substrate consisting of 2.0 volume parts of washed quartz sand (max. grain size $2 \mathrm{~mm}$ ), 1.0 volume part of standard peatbased potting substrate (type ED 73, Hermann Meyer KG, Nossen, Germany, Supporting Information S1) and approx. 0.2 volume parts of water. The potting substrate was sieved (mesh approx. 1.0-1.5 cm) to remove ancient roots and peat fibres, which would hamper fine root extraction.

The $50 \mathrm{~cm}$-high pots were custom-built for easy sampling of root systems. They consisted of two taped halves of customary HT-tubes (inner $\varnothing 110-120 \mathrm{~mm}$ ) obtained by longitudinal cutting the HT-tube on two opposite sides. The pot bottom was sealed by taping water-permeable, woven ground cover fabric (PPX® $100 \mathrm{~g} / \mathrm{m}^{2}$; Hermann Meyer $\mathrm{KG}$,
Nossen, Germany). To avoid variability of soil compaction among pots, each of the pots was filled up around the cuttings and was given exactly one sharp rap on the ground, which settled the potting mixture in a similar manner in all pots. The cuttings exceeded the pot soil level by $\leq 5 \mathrm{~cm}$, approx.

\section{Greenhouse Trial Routine}

The experiments were set up in one experimental greenhouse during the early summers of the years 2018 and 2019. The greenhouse was situated in Hetzdorf, Germany (N 50.978650 ${ }^{\circ}$, E $13.482862^{\circ} ; 350 \mathrm{~m}$ a.s.l). The closest climate station is Grillenburg: Central European temperate climate: MAT $7.8{ }^{\circ} \mathrm{C}$, AAP 901.3 mm (1981-2010) [37]. Each trial lasted 65 days to provide enough time to allow for significant treatment differentiation (cf. [13]). The trials began on 23 May 2018 and 08 May 2019 (Fig. 1, upper graph). First, all cuttings developed under normal watering for 22 days. After that, $50 \%$ of the pots were randomly selected and were exposed to the deficit watering treatment (DW), while the other $50 \%$ remained control plants under normal watering treatment (NW). Hence, the design was two way factorial (clone $\times$ watering treatment) in two compartments of the same greenhouse. The final sampling was carried out on 25 Jul 2018 or 11 Jul 2019 (Fig. 1). We excluded plants without shoot formation and plants exhibiting abnormal multiaxial growth if having no dominant, lignified shoot.

The greenhouse was operated with shade cloth, automated aeration and overhead sprinkler irrigation. However, the air temperature was not directly controlled and depended partially 


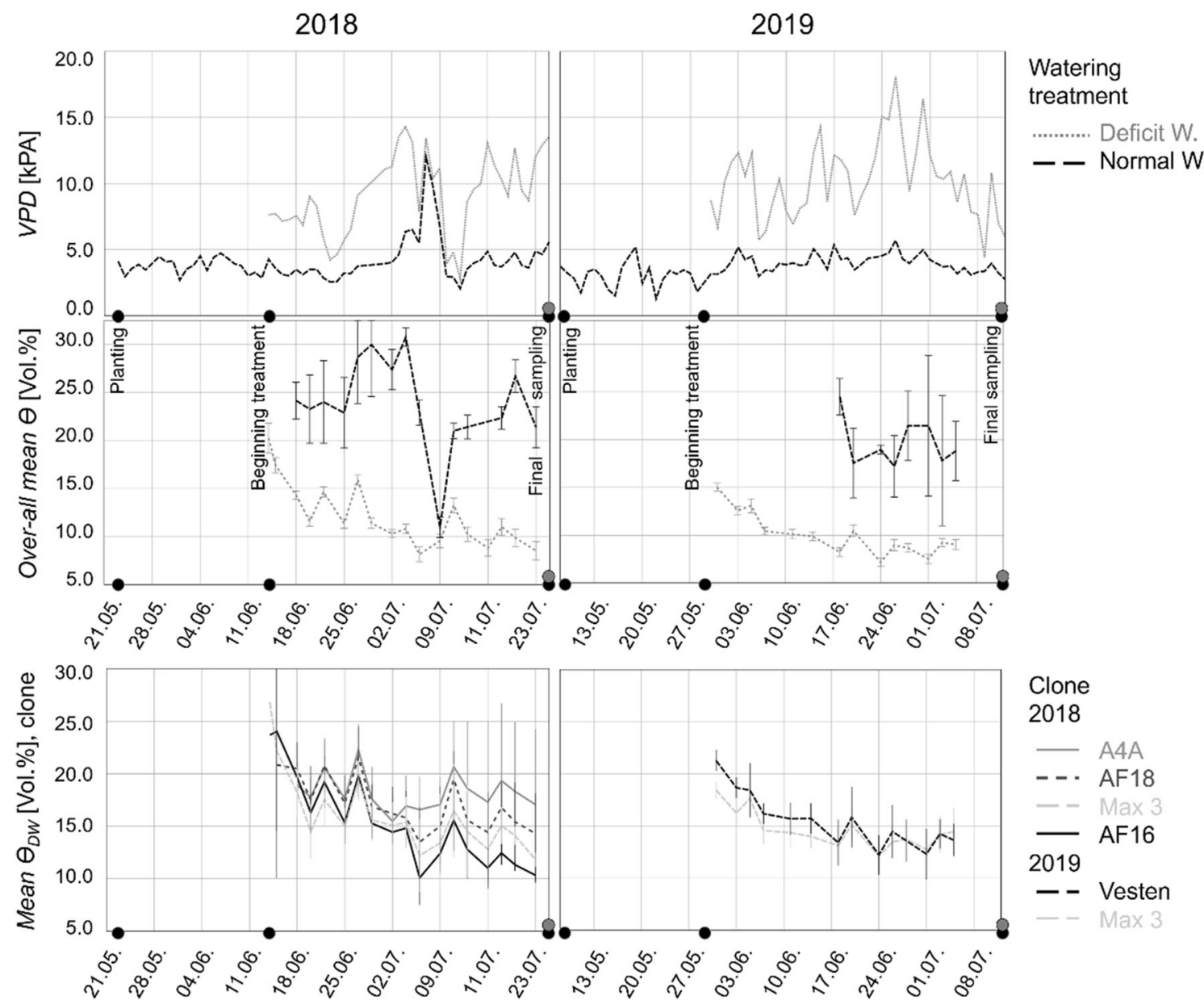

Fig. 1 Upper chart: Time sequence of water-related climatic conditions during the 2018 and 2019 greenhouse trials. Sharp drop of volumetric soil moisture content $\theta_{\mathrm{V}}(\%)$ and increase of vapour pressure deficit $V P D$ $(\mathrm{kPa})$ in the 2018 data relate to a two-day undetected malfunction of the sprinklers. The time sequence of $\theta(\%)$ shows mean values \pm standard

on the exterior weather. The 2018 and 2019 daily mean values of air temperature $T\left[{ }^{\circ} \mathrm{C}\right]$, relative air humidity $r H(\%)$, saturation vapour pressure $p_{\mathrm{W}}[\mathrm{kPa}]$, saturation vapour pressure deficit $V P D[\mathrm{kPa}]$ in the greenhouse and of the volumetric soil moisture content $\theta_{\mathrm{V}}[\mathrm{Vol} . \%]$ in the plant containers (average overall clones) are provided for the trial periods in Table 2. $T$ and $r H$ measurements, as well as the calculation of $p_{\mathrm{W}}$ and $V P D$, are described in Supporting Information $\mathrm{S} 2$.

The NW treatment was controlled by automatic sprinkler irrigation of the greenhouse to maintain $r H$ higher than $70 \%$. $\theta_{\mathrm{V}}$ of three NW pots was recorded with a portable soil moisture probe kit (ThetaProbe, ML2x, Delta-T Devices Ltd., Burwell, UK). The trials' overall mean $\theta_{\mathrm{V}}$ under NW was > $20 \%$. It was twice as high as that under DW (Table 2). The DW trees were manually watered for maintaining the mean $\theta_{\mathrm{V}}$ at approx. $10 \pm 3 \%$. The amount of water provided per pot under DW was equal for all pots and all clones. This amount was based upon periodic measurements of the mean $\theta_{\mathrm{V}}$ of a sample of every second pot across all clones (Fig. 1, upper error per measurement date, averaged over all clones. $\theta(\%)$ was measured in every third pot under the deficit watering treatment (DW) and in three pots under the normal watering treatment $(\mathrm{NW})$. Lower chart: time sequence of mean $\theta_{\mathrm{DW}}(\%)$ under $\mathrm{DW} \pm$ standard error, separately for each clone

graph). Different growth and transpiration demands resulted in different $\theta_{\mathrm{V}}$ mean values between clones under DW. The time sequences of $\theta_{\mathrm{V}}$ under DW were presented for each clone in Fig. 1, lower graph, and the respective clone means of $\theta_{\mathrm{V}}$ in Table 2 . The clone means of $\theta_{\mathrm{V}}$ under DW varied significantly, ranging from $13.3 \%$ (A4A) to $9.9 \%$ (AF16) in 2018.

It is worth noting that our standardised greenhouse trials have been set up under semi-reproducible, between-year conditions due to differing exterior weather, solar radiation or plant material conditions. Figure 1 illustrates the time sequences of the 2018 and 2019 mean $V P D(\mathrm{kPa})$ inside the greenhouse and of the mean $\theta_{\mathrm{V}}(\%)$ for both watering treatments: NW and DW. In 2018, the NW plants experienced a serious malfunction of the sprinklers for one weekend. Figure 1, left, shows the respective sharp drop of $\theta_{\mathrm{V}}$ and the peak increase of $V P D$. Furthermore, the mean values in Table 2 illustrate that overall conditions under DW were somewhat more stressful in 2019 because the mean $T$ and 
Table 22018 and 2019 mean values $( \pm$ SD) of daily mean air temperature $T\left({ }^{\circ} \mathrm{C}\right)$, rel. air humidity $r H(\%)$, saturation vapour pressure $p_{\mathrm{W}}(\mathrm{kPa})$, saturation vapour pressure deficit $V P D(\mathrm{kPa})$ and volumetric soil moisture content $\theta_{\mathrm{V}}(\mathrm{Vol} . \%)$ in two contrasting greenhouse cabins. The mean values include the trial periods between beginning the different treatments and final sampling (14.06.-25.07.2018/29.05.-11.07.2019). $\theta_{\mathrm{V}}(\mathrm{Vol} . \%)( \pm \mathrm{SD})$ clone means under deficit watering are shown with homogeneous subgroups, indicated with lowercase letters (one-factorial ANOVA with Tukey-HSD test (2018) or $t$-test (2019), $\alpha=0.05$ )

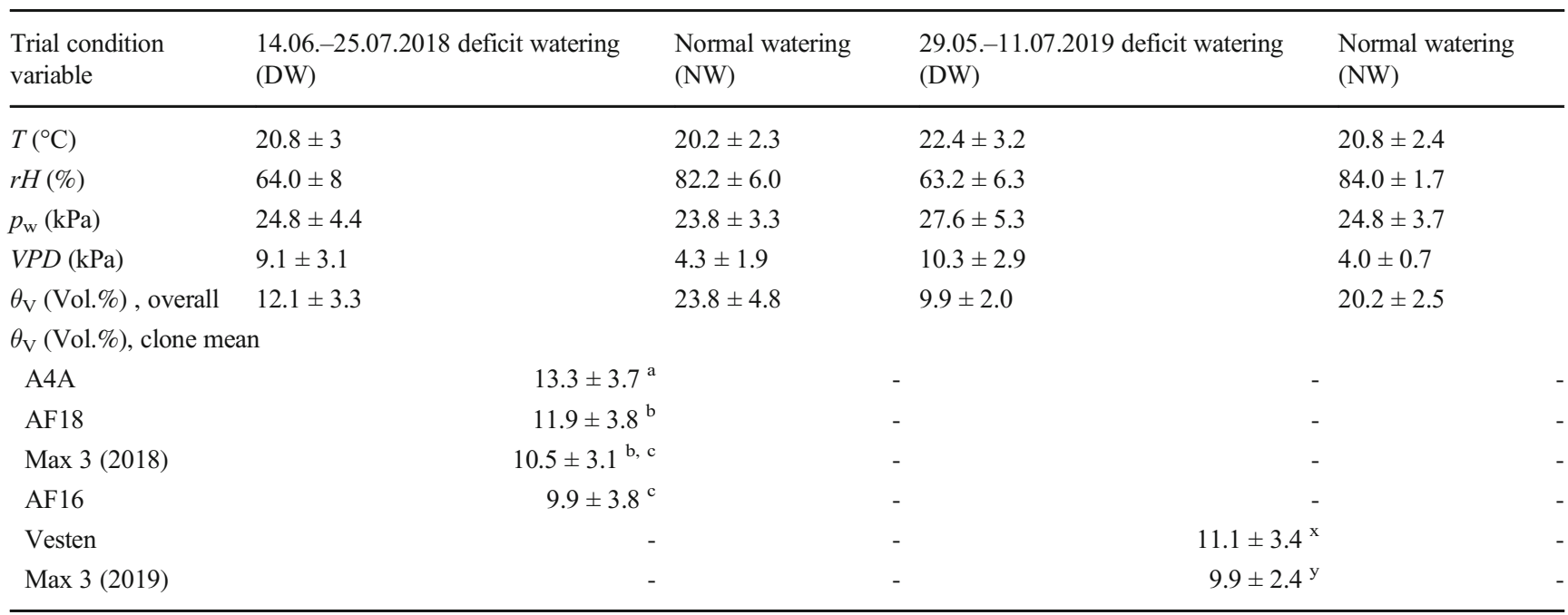

a, b, c homogeneous subgroups (Tukey-HSD test, 2018)

$\mathrm{x}, \mathrm{y}$ significantly different subgroups ( $t$-test, 2019)

mean VPD were a little higher and the mean $\theta_{\mathrm{V}}$ lower as compared with 2018.

\section{Harvesting and Measurements}

All sampled plants were carefully removed from their pot substrate and were dissected into the compartments: cutting, roots, foliage and shoots. The present work refers to shoots as the plant stems without foliage, i.e. all aboveground woody axes grown during the period of the 65-day greenhouse trial. The total pot substrate was intensively screened to extract all fine roots and remaining coarse roots. The fresh mass $\left(m_{\mathrm{f}}\right)$ was recorded for all the plant compartments immediately after dissection. Total leaf area (TLA) was measured per plant with a conveyor-belt leaf area metre (LI-3050C, Li-Cor Inc., Lincoln, NE, USA). The root systems were stored frozen until root scanning (sample images in Supporting Information S3). The computer-based root scanning system WinRHIZO ${ }^{\text {TM }}$ was used (Regent Instruments, Sainte-Foy, Québec, Canada). We accumulated data for root length $\left(\sum L_{\text {root }}\right)$ and root volume $\left(\sum V_{\text {Root }}\right)$ in five diameter classes of $0.5 \mathrm{~mm}$ width, termed hereafter: superfine roots $<0.5 \mathrm{~mm}$; fine roots $(0.5-1.0,1.0$ $1.5,1.5-2.0 \mathrm{~mm}$ ) and coarser young roots $>2.00 \mathrm{~mm}$.

All dissected plant parts were dried to a constant weight in a drying chamber $\left(102^{\circ} \mathrm{C}\right.$, for approx. three to four days $)$, and the total oven-dry biomass $\left(B M_{\text {total }}\right)$ was calculated as the sum of the oven-dry biomasses of the foliage, the shoot(s) and of the total root system $\left(B M_{\text {folia }}, B M_{\text {shoot }}, B M_{\text {root }}\right)$. The ratio of the cumulated superfine root length provided per unit leaf area was calculated as the quotient of $\sum L_{\text {root }}$ of the root diameter class $\varnothing<0.5 \mathrm{~mm}$ and $T L A\left(\mathrm{~cm} / \mathrm{cm}^{2}\right)$. Furthermore, the percent decrease of the mean individual biomass under the deficit watering treatment ( $P$ Diff- $\left.B M_{\text {total }}\right)$ was calculated as follows:

$\frac{B M_{\mathrm{NW}}-B M_{\mathrm{DW}}}{B M_{\mathrm{NW}}} \times 100$

\section{Statistical Analysis}

The univariate GLM algorithm of IBM® SPSS® Statistics for Windows, v. 27 (IBM Corp., Armonk, NY, USA) was used to perform two factorial ANOVAs with the two factors 'watering' (factor levels: DW, NW) and 'clone'. The interaction factor 'clone $\times$ watering' was also tested within the ANOVA models. To avoid potential bias by the effect of between-year differences, only data for the year 2018 of the clones A4A, AF16, AF18 and Max 3 were used in the ANOVAs. Between-year comparisons of the mean values for 2018 and 2019 were carried out with $t$-tests for the data of Max 3, which was the only clone tested in both years.

The dependent variables were (i) the biomass $B M$ fractions (\%) of the three plant compartments of roots, shoots or foliage, (ii) the cumulated root volumes $\sum V_{\text {root }}\left[\mathrm{cm}^{3}\right]$ of the five root diameter classes, and (iii) the ratio of cumulated superfine root length per total leaf area $\left(\sum L_{\text {root }} \varnothing<0.5 \mathrm{~mm}\right.$ :TLA $)$. 


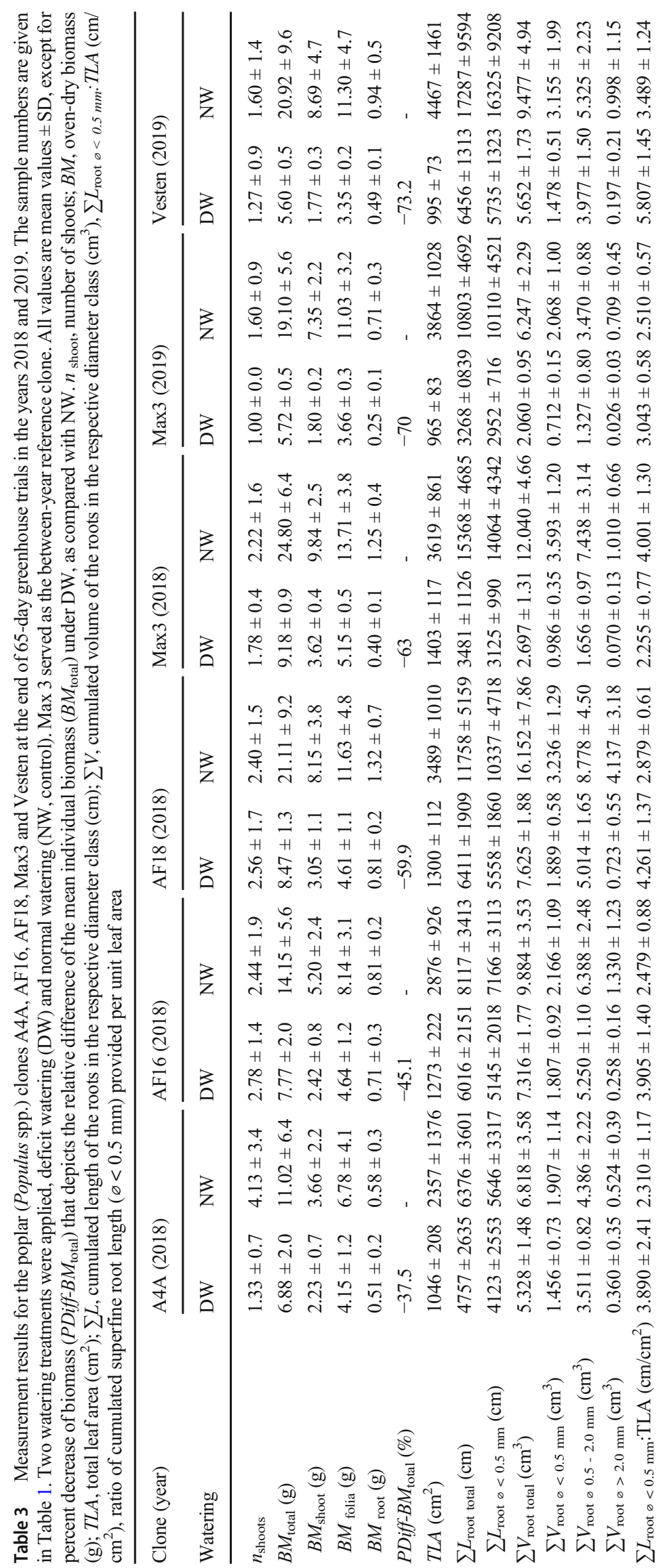


Fig. 2 Clone-specific mean single-plant biomass values ( $B M$, oven-dry (g), given with SD) under normal and deficit watering treatments $(\mathrm{NW}, \mathrm{DW})$ at the end of a 65-day greenhouse trial on the early poplar development. Corresponding to the upper diagram, the lower diagram shows the mean relative $B M$ fractionation (\%) to roots, shoots and foliage biomass. Poplar (Populus spp.) clone names and the respective year of the trial given on the left
Table 4 ANOVA test results as significance ( $p$-value), effect size (reduced $\eta^{2}$ ) and $R^{2}$. The models were all saturated with two main effect factors 'watering' (2-factor levels: deficit and normal watering) and 'clone' (6 levels), and with the interaction factor 'clone $\times$ watering'. Upper part: ANOVAs with three dependent variables for the percent biomass fractions (\%-BM $(\%))$ of roots, shoots or foliage. Central part: ANOVA series with five dependent variables that refer to cumulated root volume $\left(\sum V_{\text {root }}\right.$ $\left.\left(\mathrm{cm}^{3}\right)\right)$ of five subsequent root diameter classes. Lower part: ANOVA for the dependent variable 'cumulated superfine root length per total leaf area ratio' $\left(\sum L_{\text {root } \theta<0.5 \mathrm{~mm}}:\right.$ TLA $(\mathrm{cm} /$ $\left.\mathrm{cm}^{2}\right)$ )
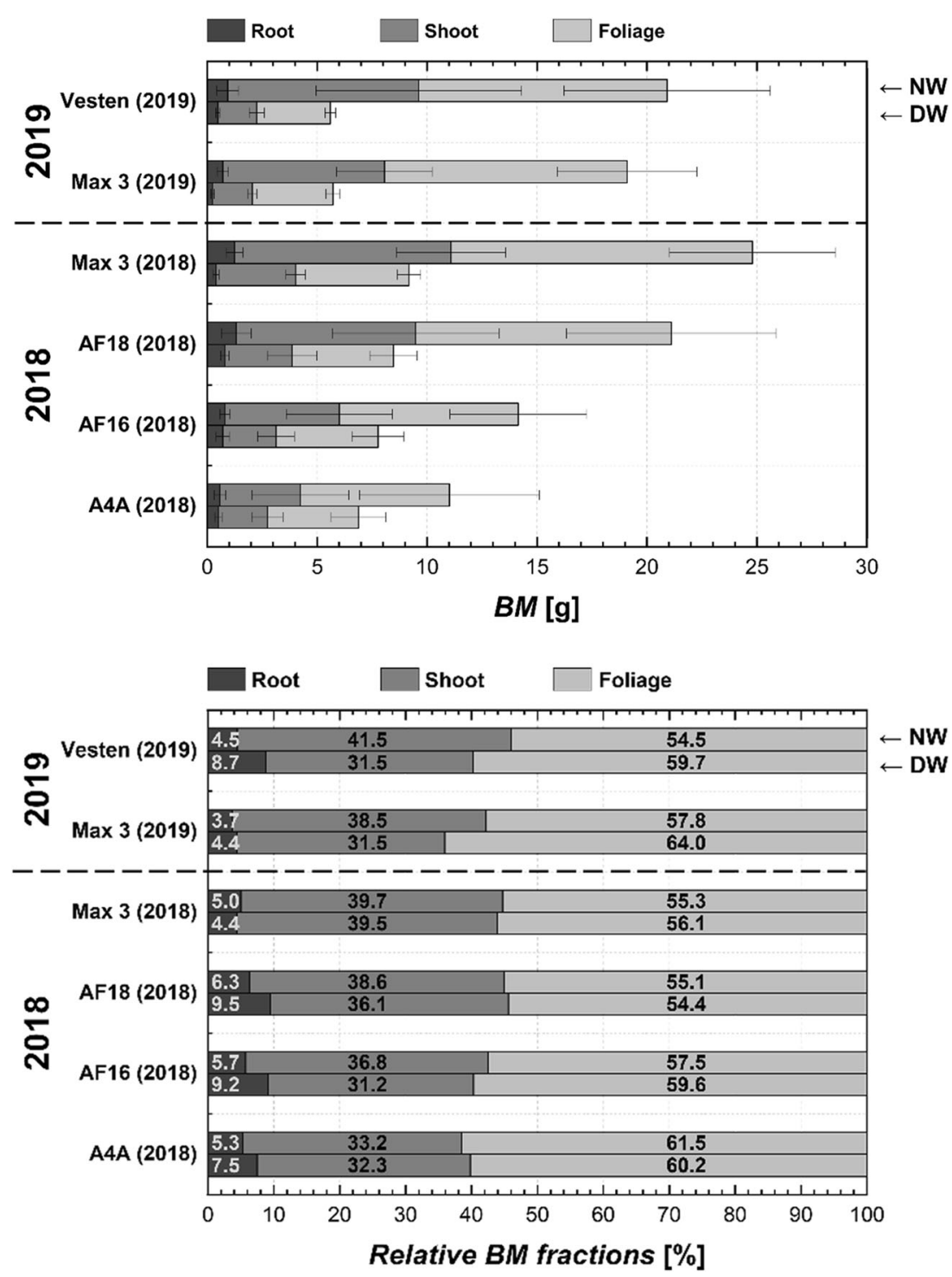

\begin{tabular}{|c|c|c|c|c|c|c|c|c|}
\hline \multirow[t]{2}{*}{ Dependent variable } & \multicolumn{2}{|c|}{ Factor 'watering' } & \multicolumn{2}{|c|}{ Factor 'clone' } & \multicolumn{2}{|c|}{ "Clone $\times$ watering' } & \multirow[t]{2}{*}{$R^{2}$} & \multirow[t]{2}{*}{ Corr. $R^{2}$} \\
\hline & $p$ (sig.) & red. $\eta^{2}$ & $p$ (sig.) & red. $\eta^{2}$ & $p$ (sig.) & red. $\eta^{2}$ & & \\
\hline$\%-B M_{\text {root }}$ & 0.002 & 0.205 & 0.002 & 0.136 & 0.116 & 0.089 & 0.334 & 0.260 \\
\hline$\%-B M_{\text {shoot }}$ & $<0.001$ & 0.357 & $<0.001$ & 0.167 & 0.126 & 0.086 & 0.462 & 0.402 \\
\hline$\%-B M_{\text {foliage }}$ & 0.002 & 0.204 & 0.185 & 0.028 & 0.751 & 0.019 & 0.237 & 0.152 \\
\hline$\sum V_{\text {root }}<0.5 \mathrm{~mm}$ & 0.050 & 0.115 & $<0.001$ & 0.298 & 0.003 & 0.196 & 0.451 & 0.391 \\
\hline$\sum V_{\text {root }} 0.5 \leq 1.0 \mathrm{~mm}$ & 0.008 & 0.166 & $<0.001$ & 0.243 & $<0.001$ & 0.259 & 0.472 & 0.415 \\
\hline$\sum V_{\text {root }} 1.0 \leq 1.5 \mathrm{~mm}$ & 0.006 & 0.177 & $<0.001$ & 0.187 & 0.059 & 0.109 & 0.368 & 0.299 \\
\hline$\sum V_{\text {root }} 1.5 \leq 2.0 \mathrm{~mm}$ & 0.006 & 0.178 & $<0.001$ & 0.276 & 0.193 & 0.071 & 0.415 & 0.351 \\
\hline$\sum V_{\text {root }}>2.0 \mathrm{~mm}$ & $<0.001$ & 0.299 & $<0.001$ & 0.233 & 0.004 & 0.195 & 0.509 & 0.453 \\
\hline$\sum L_{\text {root } \varnothing<0.5 \mathrm{~mm}}:$ TLA & 0.830 & 0.014 & 0.057 & 0.056 & $<0.001$ & 0.231 & 0.267 & 0.185 \\
\hline
\end{tabular}


Box plots, Kolmogorov-Smirnov and Shapiro-Wilk test statistics were consulted to check normality using SPSS's explorative analysis algorithm. Violation of the assumption of normality was found only in exceptional cases. Also, Levene's test statistics were partially significant $(\alpha=0.05)$. For instance, it was significant for the $\%-B M_{\text {root }}$ fraction, insignificant for the $\%-B M_{\text {shoot }}$ fraction and highly significant for the $\%-B M_{\text {foliage }}$ fraction. However, the sample size of the tested groups was similar, and the deviation from the homogeneity of variances was found to be caused by a similar pattern of skewness. We concluded that the assumptions of normality and of homogeneity of variances were not perfectly met, but that the ANOVAs were sufficiently robust. Plots were generated with SPSS or with OriginPro 2019b, v. 9.6.5.169 (OriginLab Corporation, Northampton, MA, USA).

\section{Results}

\section{Biomass Allocation and Fractionation}

All clones included both mono- and multi-axially growing plants. The mean number of shoots $\left(n_{\text {shoots }}\right)$ per plant is presented in Table 3. On average, Max 3 and Vesten developed less shoots, and their $n_{\text {shoots }}$ was lower under deficit watering treatment (DW). AF16 and AF18 developed more shoots, and their $n_{\text {shoots }}$ was lower under normal watering treatment (NW). Because of the variability of $n_{\text {shoots }}$ between the clones and between the treatments, the root-to-shoot length ratio was not suitable to reflect the biomass allocation correctly. This ratio is given with other additional data in Supporting Information S4.

The mean single plant oven-dry biomass $B M_{\text {total }}$ grown over 65 days is depicted in Table 3 and Fig. 2. Under normal watering treatment, $B M_{\text {total }}$ varied between $11.02 \mathrm{~g}$, for clone $\mathrm{A} 4 \mathrm{~A}$, and $24.80 \mathrm{~g}$ for clone Max 3 in 2018. Under deficit watering treatment, $B M_{\text {total }}$ was lower for all clones. The respective percent decrease (PDiff- $B M_{\text {total }}$, Table 3 ) varied between $-37.5 \%$ (A4A) and $-73.2 \%$ (Vesten), and the fastergrowing clones AF18, Max 3 and Vesten had the greatest reductions. This can partially be related to different soil volumetric water contents that had developed under common watering but with differing water utilisation characteristics by different clones (see "Materials and Methods" for method description of the deficit watering treatment, and Fig. 1, lower graph, Table 2).

In all deficit watering samples, the mean biomass of all three plant components, $B M_{\text {root }}, B M_{\text {shoot }}$ and $B M_{\text {foliage, }}$, was reduced (Fig. 2, upper graph). However, the scaling of that decrease was not equal among these plant components, and this was illustrated by the variable shift in their mean relative biomass contribution \%-BM to the total biomass (Fig. 2, lower diagram). Accordingly, the main effect factor 'watering' was at least very significant in the three ANOVAs for \%- $B M_{\text {root}}$,

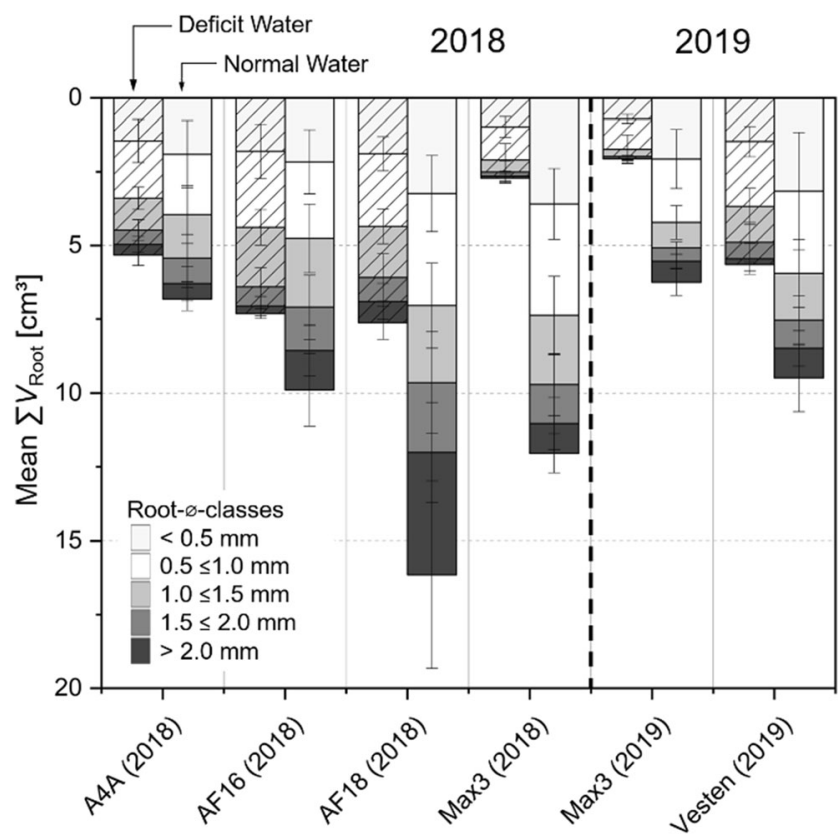

Fig. 3 Mean cumulated root volume $\left(\sum V_{\text {root }}\left(\mathrm{cm}^{3}\right)\right)$ of five root diameter classes, given for each poplar clone subsample under deficit or normal watering treatment (deficit water, normal water). Whiskers $=\mathrm{SD}$

for $\%-B M_{\text {shoot }}$ and for $\%-B M_{\text {foliage }}$ (Table 4, data for 2018). The other main effect factor 'clone' was significant only for $\%-B M_{\text {root }}$ and $\%-B M_{\text {shoot }}$, and there were no significant interaction effects in all three ANOVAs. The inter-sectional hybrid Max 3 had generally a lower root biomass fraction as compared with the $P . \times$ euramericana clones. Irrespective of the lacking significance of the interaction factor on $\%-B M_{\text {root }}$, there was another remarkable difference between the $P . \times$ euramericana clones and Max 3 in 2018. While the $P . \times$ euramericana clones showed a clearly increased mean $\%-B M_{\text {root }}$ under deficit watering treatment (A4A: $+42 \%$, AF16: + 61\%, AF18: + 61\%), Max 3 represented the only case for which the mean $\%-B M_{\text {root }}$ was reduced under deficit watering. However, this reduction amounted to only $-12 \%$. In the other year 2019, Max 3 showed an increase of $+19 \%$. The $P . \times$ euramericana clone Vesten, which was grown in 2019 with Max 3, had $+93 \%$ increase. Overall, the $\%-B M_{\text {root }}$ of Max 3 responded less plastically to the deficit watering than that of the $P . \times$ euramericana clones. Also, Max 3's differences between 2018 and 2019 were only significant under the normal watering treatment (5.0\% vs. $3.7 \%, t$-test: $p=0.031$ ). Under deficit watering, \%-BM root of Max 3 was equal between the years at $4.4 \%$ ( $t$-test: $p=0.906)$.

The percent biomass fractions of the aboveground plant parts were dominated by the foliage (Fig. 2, lower diagram). The biomass fraction of the foliage varied between 54.4 and $64.0 \%$ and that of the shoots between 31.2 and $41.5 \%$, depending on the watering treatment and clone. Under deficit watering, all clones showed an almost equal or an increased $\%-B M_{\text {foliage }}$ as compared with normal watering. Furthermore, 
the change of $\%-B M_{\text {foliage }}$ under deficit watering treatment corresponded with the change of $\%-B M_{\text {shoot }}$. In detail, the clones showed basically two response types of the aboveground biomass fractionation under DW. Either there was virtually no change of both fractions (A4A, AF18, Max 3 2018 ), or the mean $\%-B M_{\text {shoot }}$ decreased while the mean $\%-B M_{\text {foliage }}$ fraction increased (AF16, Vesten, Max 32019 ).

\section{Root Differentiation}

The mean cumulated single plant root volume $\sum V_{\text {root }}$ per clone (Table 3, Fig. 3) showed a similar variation as compared with the biomass. In detail, the clones that grew faster under normal watering showed a greater reduction of the total $\sum V_{\text {root }}$ under deficit watering. Max 3 had the overall greatest reduction by $-77.6 \%$ in 2018 , AF18 a $-52.8 \%$ reduction and A4A only $-21.9 \%$ (cf. total bar lengths in Fig. 3).

The $\sum V_{\text {root }}$ of the root diameter classes ( $\oslash$ ) including superfine, fine and coarser young roots was not equally affected by deficit watering. Particularly the $P . \times$ euramericana clones A4A, AF16 and AF 18 had a smaller reduction of the superfine root volume as compared with the coarser young root volume. Also, the significance of the respective main effect factor

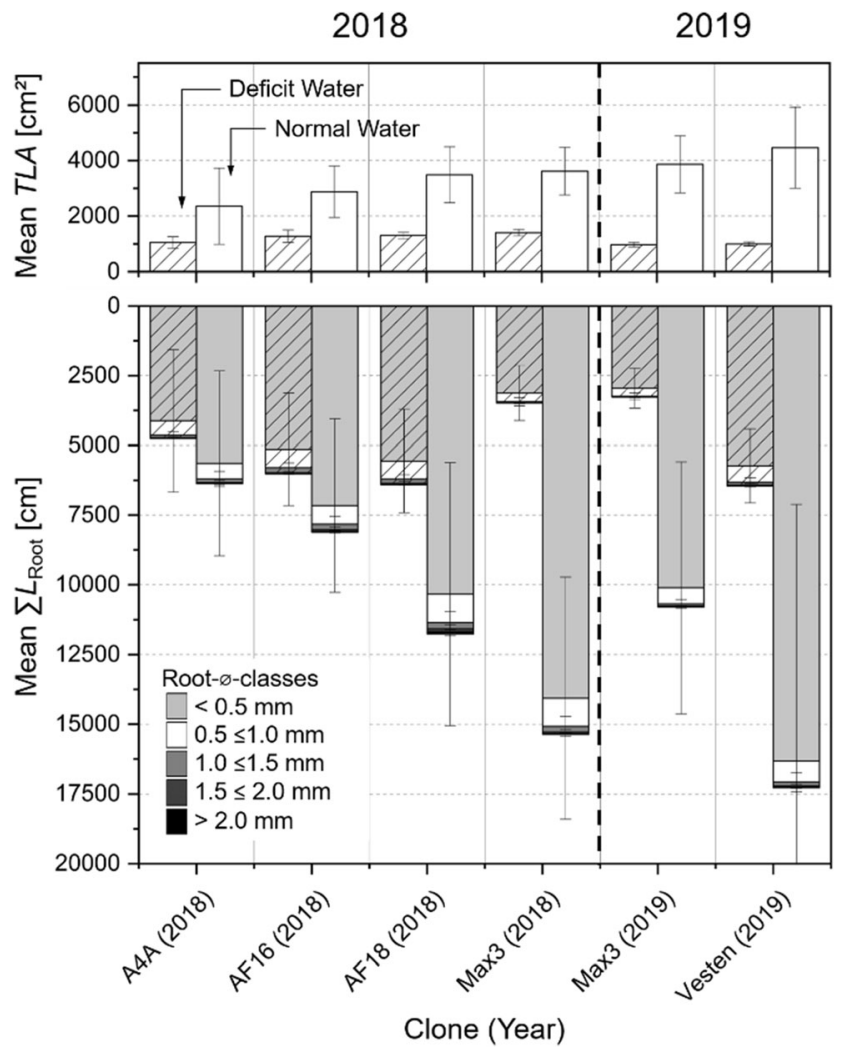

Fig. 4 Mean total leaf area $\left(T L A,\left(\mathrm{~cm}^{2}\right)\right)$ and mean cumulated root length $\left(\sum L_{\text {root }}(\mathrm{cm})\right)$ of five root diameter classes, given for each poplar clone subsample under deficit or normal watering treatment (deficit water, normal water). Whiskers $=\mathrm{SD}$. To illustrate the ratio of cumulated root length provided per unit leaf area, $1 \mathrm{~cm}$ of $\sum L_{\text {root }}$ corresponds to the scaling of $1 \mathrm{~cm}^{2}$ of $T L A$ on the $Y$-axes 'watering' on $\sum V_{\text {root }}$ increased steadily in the ANOVA series from the class of superfine roots $(p=0.049$, Table 4$)$ to the class of coarser young roots $(p<0.001)$. Accordingly, the watering had its greatest effect size in the ANOVA for $\sum V_{\text {root }}$ of the coarser young roots (reduced $\eta^{2}=0.299$, Table 4). However, there were also highly significant differences between the clones or highly significant 'watering $\times$ clone' interaction effects. The interaction effect 'clone $\times$ watering' was not significant in the ANOVAs for $\sum V_{\text {root } 1.0 \leq 1.5 \mathrm{~mm}}$ and $\sum V_{\text {root } 1.5 \leq 2.0 \mathrm{~mm}}$. This indicates that the clone-specific differences in $\sum V_{\text {root }}$ depended significantly on the watering in the superfine and coarser root diameter classes, but not in the fine root classes.

A remarkable difference appeared between Max 3 and the P. $\times$ euramericana clones grown in 2018. While Max 3 had the highest mean superfine root volume and limited coarser young root volume under normal watering, AF18 had a high superfine root volume but also the greatest coarser young root volume (Fig. 3). Furthermore, AF18 had a smaller reduction of the mean superfine root volume under deficit watering than Max 3. The comparison of the mean $\sum V_{\text {root }}$ for Max 3 between the years 2018 and 2019 demonstrated that conditions resulted in significantly reduced root growth under normal watering in 2019 ( $t$-test: $p=0.024)$ but not under deficit watering in 2019 ( $t$-test: $p=0.306)$. Therefore, the $\sum V_{\text {root }}$ results of the clone Vesten, which was tested only in 2019 , cannot be directly compared with the other $P . \times$ euramericana clones grown in 2018. However, in all root diameter classes and under both watering treatments in 2019, the root volume of Vesten was distinctly greater than that of Max 3. Furthermore, Vesten showed a smaller reduction of $\sum V_{\text {root }}$ under deficit watering as compared with Max 3.

The results for the ratio of cumulated superfine root length allocated per total leaf area are given in Table 3 $\left(\sum L_{\text {root } \theta<0.5 \mathrm{~mm}}:\right.$ TLA $\left.\left(\mathrm{cm} / \mathrm{cm}^{2}\right)\right)$, and they are illustrated with Fig. 4. The mean values varied between 2.3 and $4.0 \mathrm{~cm} / \mathrm{cm}^{2}$ for Max 3 or between 2.3 and $5.8 \mathrm{~cm} / \mathrm{cm}^{2}$ for $P . \times$ euramericana hybrids. In 2018, all $P$. $\times$ euramericana clones showed an increased ratio under deficit watering treatment by approx. + $1.5 \mathrm{~cm} / \mathrm{cm}^{2}$. Among them, AF18 had the highest ratio. In contrast, Max 3 had the highest ratio of superfine root length per unit leaf area under normal watering, $4.0 \mathrm{~cm} / \mathrm{cm}^{2}$. And with $2.3 \mathrm{~cm} / \mathrm{cm}^{2}$, the Max 3 plants had ratio reduced by almost $50 \%$ under deficit watering. The main effect factors 'watering' and 'clone' on the ratio $\sum L_{\text {root } \diamond<0.5 \mathrm{~mm}}$ :TLA were not significant (ANOVA, Table 4). However, in accordance with the variability of clone differences under normal and deficit watering treatments, the interaction factor was highly significant $(p<0.001)$. In the year 2019, Max 3 showed an increased ratio of superfine root length per unit leaf area under deficit watering. But that difference was small, 2.5 vs. $3.0 \mathrm{~cm} / \mathrm{cm}^{2}$. The between the year difference of Max 3 was significant only for the normal watering treatment ( $t$-test: $p=0.033$ ). The ratio was lower in 2019 than in 
2018. Max 3's between-year difference was not significant for deficit watering $(p=0.072)$. Under both watering treatments in 2019 , the $P$. $\times$ euramericana clone Vesten exhibited the overall greatest mean ratio of superfine root length per unit leaf area among all tested clones.

\section{Discussion}

\section{Different Plasticity of Biomass Allocation Under Water Deficit}

The first objective of the study was to assess the growth and biomass allocation response of young poplar plants of different clones to a common deficit watering treatment. Poplar trees that grow under water deficits in natural environments favour root development at the expense of the aboveground biomass [16]. This is due to a functional adaptation to exploit water from bigger or deeper soil volumes in combination with reducing the evapo-transpirational area $[16,38]$. But clonespecific differences in that change of biomass allocation must be expected in the drought adaptation of SRC trees [31,35]. Even though the present early-stage poplars grew only in a limited pot volume for 65 days, clone differences in the rootto-shoot allocation of biomass were significant. Such differences have been previously proposed for young poplars growing from cuttings [13]. However, drought experiments did often not confirm the hypothesis of an increase in the rootto-shoot ratio [15]. For instance in an experiment with poplars, only the driest of the treatments at $100 \%, 50 \%, 40 \%$ and $30 \%$ of field capacity induced an increase in the root-to-shoot ratio in all of the three tested clones [6]. This was presumably due to an influence of the stress intensity in interaction with the specific clones' sensitivity (cf. [39]). Also, adaptations to greenhouse conditions, like those described for specific leaf area [40, 41], may account for bias. For instance, the between treatment differences of the greenhouse air vapour pressure deficit $(V P D)$ (Fig. 1, Table 2) may have resulted in changes in the leaf physiology [42]. In the present study, the impact of the water shortage caused a sharp decrease in total biomass production in the early-stage plants that grew under deficit watering. Hence, we can assume that the stress resulting from the deficit watering treatment was strong enough to reveal clone $\times$ watering differences.

Our results suggest that the increase of $\%-B M_{\text {root }}$ of young poplar plants was either not at the expense of $\%-B M_{\text {foliage }}$ but at the expense of $\%-B M_{\text {shoot }}$, or that the $\%-B M_{\text {shoot }}$ and $\%-B M_{\text {foliage }}$ were reduced in approximately the same quantity, only. In accordance, the stochastic effect size of the factor 'watering' in the ANOVA was higher on \%-BM shoot than on $\%-B M_{\text {foliage. }}$ The meta-study of Eziz et al. [38] showed that relative to herbaceous plants, drought would have a larger detrimental impact on the leaf biomass fraction $\left(\%-B M_{\text {foliage }}\right)$ of woody plants. However, the present results were not contradictory to the meta-study of Eziz et al. [38] because the very young poplars were likely still in a different physiological status as compared with established SRC trees. Our young poplars had not as much time to accumulate large amounts of woody biomass. The present root biomass fraction was still very low after 65 days of growth in pots as compared with 1 -year-old SRC trees [12]. First, the coarse roots were still lacking. At the end of the first season in the field, coarse roots can provide an approximate biomass fraction between 20 and $30 \%$, while the fine root fraction would remain roughly at the level below $10 \%$ [12]. In contrast, the total root biomass fraction of all clones was still below $10 \%$ in the present greenhouse experiment. Second, one might speculate that the small pot resources had potentially a limiting effect on the root development as compared with field conditions. Only established SRC trees would develop stems and wide, coarse root systems, upon which they rely in drought periods, and their root mass fraction likely decreases slowly over the years $[12,14]$.

The highly significant effect of the factor 'clone' in the respective ANOVA underscores that the present clones differed in their root biomass fraction $\%-B M_{\text {root }}$. The present $P . \times$ euramericana clones differed from Max 3 , which had the lowest $\%-B M_{\text {root }}$ among the tested clones. This was in line with the first hypothesis of the present study. However, the interaction factor 'clone $\times$ watering' became insignificant for 2018. Therefore, a lack in plasticity cannot be confirmed for Max 3 based on the present $B M_{\text {root }}$ allocation data. In addition, its' deficit watering response of $\%-B M_{\text {root }}$ was not equal between the years 2018 and 2019. But this outcome contrasts to the superfine root allocation per unit leaf area (see Results), which revealed significant interaction effects and a lack in plasticity for Max 3. In addition, Max 3 never showed a clear increase of $\%-B M_{\text {root }}$ under deficit watering and only small differences between normal and deficit watering treatments in both years. Therefore, the capability to plastically adapt the root biomass fraction under water deficits should not be assumed for Max 3. A lack in plasticity of carbon allocation under water deficits has been described for another intersectional Tacamahaca hybrid (P. trichocarpa $\times$ P. deltoides) that was grown in comparison with a $P . \times$ euramericana clone in a largescale plantation trial [31]. Potentially, the genomic contribution of the $P$. trichocarpa parent entails the lack in plasticity of that hybrid because $P$. trichocarpa is adapted to climates that are characterised moist Pacific Ocean air [43]. But a lack in plasticity of root biomass allocation cannot be generalised for all Tacamahaca species because the variability of drought responses may be very important even among clones of the same hybrid or species [43]. However, one might speculate that different evolutionary adaptations might be relevant. The poplars of the section Tacamahaca are mainly found in the northern latitudes, even to the northern limits of 
tree growth while $P$. nigra and $P$. deltoides have native areas that comprise the warm-temperate and even the northern subtropical zones [27]. It was known that the Tacamahaca species $P$. trichocarpa and $P$. balsamifera may have a rather shallow and extensive root system as compared with $P$. $\times$ euramericana or P. nigra [14, 32-34]. The genome of the present clone Max 3 consists of genetic material of P. nigra and of P. maximowiczii, another Tacamahaca species. Potentially, this genome contribution of a Tacamahaca species can explain the relatively high superfine and fine root biomass as well as the high ratio of superfine root length per unit leaf area of Max 3 under normal watering treatment.

\section{Root Differentiation Is Subject to 'Clone $\times$ Watering' Interaction Effects}

Another objective of this study was to assess whether there were clone differences in the composition of the root systems and whether the cumulated root volume $\sum V_{\text {root }}$ of different root diameter classes (ø) varied in response to deficit watering treatments. Neither question could be answered with certainty because the 'clone $\times$ watering' interaction effect was very significant on the superfine and the coarser root diameter classes in the ANOVA series for $\sum V_{\text {root }}$, and because root development was possibly not yet finalised after the trial period of 65 days. However, the significance of the main effect factor watering increased from the classes of the superfine to that of the coarser young roots. Accordingly, the effect size of the deficit watering treatment was greater on the root volume of the coarser young roots (Table 4). But it cannot be concluded that the cumulated volume of coarser young roots was more sensitive to water deficits than that of fine root diameter classes. As discussed in the previous chapter, the coarser roots may develop only later in the first season of poplar growth [12], and the present investigation only considered the first 65 days of growth. Hence, it was possible that the present significant clone differences in the reduction of $\sum V_{\text {root }}$ of coarser roots under deficit watering treatment were only the consequence of different deceleration of coarser root growth. Unlike the effect of the factor 'watering', that of the factor 'clone' on $\sum V_{\text {root }}$ was highly significant throughout all root diameter classes. Similarly, it was well known that the rooting of poplar cuttings is under strong genetic control [9]. But regarding the 'clone $\times$ watering' interaction effect on $\sum V_{\text {root }}$ of different root diameter classes, it must be concluded that the clone differences in root differentiation were subject to changes during deficit watering treatments. For instance, Max 3 had a high superfine root fraction only under normal watering, while the P. $\times$ euramericana clones Vesten and AF18 were the two studied clones that had the greatest potential to develop superfine roots under normal watering as well as deficit watering treatments. But Vesten had fewer coarser roots than the clones AF18 and AF16. The role of coarser young roots is presumably to form a grid of long-living roots, which can be the origin of new fine roots during improving water availability. It was well known that the fine roots lose their water absorption ability after few days or weeks [44]. We assumed that early-stage plants of clones like AF18, which differentiate more superfine as well as coarser young roots during water deficits, are better adapted for exploiting residual soil water during spring drought and new water during soil rehydration.

\section{Superfine Root Allocation per Unit Leaf Area}

The differences between the studied clones in their responses to a common watering deficit during early root growth may be more apparent when assessing the ratio of cumulated superfine root length per total leaf area $\sum L_{\text {root } \theta<0.5 \mathrm{~mm}}$ :TLA [35]. In the present data for 2018, only the interaction factor 'clone $\times$ watering' had a significant effect on that ratio. This indicated a significantly different adaptation of the clones under water deficit. Hence, the third hypothesis was confirmed. The P. $\times$ euramericana clones Vesten and AF18 had the overall greatest ratio of superfine root length per unit leaf area. Max 3 showed, in contrast to all other clones in 2018, no increase of that ratio during drought, but its ratio was approx. $30 \%$ higher than that of AF18 during normal watering. A likewise difference between a Tacamahaca poplar and a $P . \times$ euramericana clone was described by Pregitzer et al. [35] for the poplar cultivars Tristis and Eugenei. Their average ratios of fine root length per unit leaf area overall watering and nitrogen treatments were $14.50 \mathrm{~cm} / \mathrm{cm}^{2}$ or $4.03 \mathrm{~cm} / \mathrm{cm}^{2}$. It was widely accepted that the allocation of more fine roots in wider and deeper soil profiles provides improved water access during moderate soil water deficits. Therefore, poplar clones like Max 3, which lack the plasticity to increase the ratio of superfine root length per unit leaf area during deficit watering, are probably not well suited for plantation establishment on sandy soils during spring droughts.

\section{Traits for Assessing Drought Response of Early-Stage Poplars}

A separate objective of the present study was to discuss the value of the measured traits for assessing drought response of poplar clones in the early stage after planting. The example of the two studied clones AF18 and Max 3 illustrates that a higher number of shoots $\left(n_{\text {shoots }}\right)$ compromised the dominance of the longest shoot and also the meaningfulness of the root-to-shoot length ratio. Specifically, AF18 showed the greater $n_{\text {shoots }}$ than Max 3 and the lower length of the longest shoot. But because both clones had high total biomass values and high shoot biomass values (Table 3 ), it was not possible to decide whether the shorter or the longer mean shoot length or the high or the low root-to-shoot length ratio were more desirable. Also, total biomass and 
Table 5 SRC field establishment result in a field trial in Central Europe on sandy soil (N $48.403759^{\circ}, \mathrm{E} 16.987345^{\circ}, 155$ $\mathrm{m}$ a.s.l., groundwater $120 \mathrm{~cm}$ b.g.l.). The percent plant loss (\%) is given for the first growing season, diameter at breast height and tree height were measured after the 2 nd growing season $\left(\mathrm{DBH}_{2}\right.$ and $\left.h_{2}\right)$

\begin{tabular}{llllll}
\hline $\begin{array}{l}\text { Poplar } \\
\text { clone }\end{array}$ & \%-loss (after 1st year) & Mean $\mathrm{DBH}_{2}(\mathrm{~cm})$ & Max. $D B H_{2}(\mathrm{~cm})$ & Mean $h_{2}(\mathrm{~m})$ & Max. $h_{2}(\mathrm{~m})$ \\
\hline AF16 & 25 & 6.7 & 9.6 & 5.9 & 7.4 \\
AF18 & 5 & 7.3 & 10.9 & 6.3 & 7.6 \\
Max 3 & 30 & 4.9 & 7.3 & 6.1 & 7.8 \\
Vesten & 13 & 7.3 & 9.7 & 6.7 & 7.9 \\
\hline
\end{tabular}

the drought-related decrease of biomass productivity of a clone during drought must be interpreted with caution. As noted by others [7], productive poplar genotypes show a large reduction of biomass growth under drought. And the present data on percent decrease of the mean individual biomass under deficit watering ( $P$ Diff- $\left.B M_{\text {total }}\right)$ was fully in line with these findings. However, using this PDiff$B M_{\text {total }}$ result alone to distinguish different levels of drought tolerance can be misleading. First, higher growth rates in later years may fully compensate early losses [31]. Hence, a relatively high percent loss of $B M_{\text {total }}$ during deficit watering was potentially acceptable if this clone was more productive than other clones over years or if its' biomass reduction in a drought experiment corresponds with above-average biomass growth under normal watering. The latter criterion was fulfilled by the clones Max 3, Vesten, AF18 and partially by AF16. But due to the lack of plasticity in the root biomass fraction, Max 3 cannot be considered drought tolerant during the SRC plantation establishment on dry sites. The consequence of this lack in root plasticity becomes even more apparent when considering the overall finer root structure and the large relative reduction of fine root length under deficit watering treatments. The most elucidating trait in the present investigation was the ratio of cumulated superfine root length per unit leaf area $\left(\sum L_{\text {root }} \varnothing<0.5 \mathrm{~mm}:\right.$ TLA $\left.\left[\mathrm{cm} / \mathrm{cm}^{2}\right]\right)$.

A certain risk for drought-related operational losses was predicted for Max 3 on the basis that it lacked adaptation of the ratio $\sum L_{\text {root } \varnothing<0.5 \mathrm{~mm}}$ :TLA in the study. Currently, a 2year growth result study in a parallel operational SRC field trial was available to allow the comparison of four of the present clones AF18, AF16, Vesten and Max 3 (Table 5). The SRC field (N 48.403759 ${ }^{\circ}$, E $16.987345^{\circ}, 155 \mathrm{~m}$ a.s.1.) was situated in a Central European region, which is exposed to a risk for spring droughts, on sandy soil (gleysol, classification after IUSS Working Group WRB [45]). The groundwater level was at $120 \mathrm{~cm} \mathrm{b.g.1.} \mathrm{Max} 3$ had the highest percent loss of plants $(30 \%)$ in the 1 st season post planting, and it had the lowest mean stem diameter after the 2nd season $(4.9 \mathrm{~cm})$. This indicated that Max 3 was indeed less favoured by the dry conditions for SRC establishment.
AF18 and Vesten showed the best results, and AF16 results were intermediate. Overall, that field result reflected the outcome of the risk assessment of the present greenhouse trial very well.

\section{Conclusions}

There were significant clone differences in the biomass fractionation response and in adjusting the allocation of fine root length per unit total leaf area to common deficit watering treatments. The most contrasting clones were the two P. $\times$ euramericana clones AF18 and Vesten, and the $P$. nigra $\times P$. maximowiczii clone Max 3, all showing robust early growth potential. However, Max 3 showed the smaller total root volume, the smaller coarser young root volume and a lack in plasticity of the biomass allocation to fine roots. All $P . \times$ euramericana clones showed an increase of fine root length per unit total leaf area under deficit watering treatments. Hence, the clone Max 3, although showing fast early growth, bears uncertainty for plantation establishment under dry spring planting conditions. With a focus on plasticity of early-stage poplars that involved biomass allocation to roots in balance with the total leaf area during deficit watering treatments, a drought risk assessment for the SRC establishment was supported.

Abbreviations AAP, Average annual precipitation; $B M$, Oven-dry biomass, or dry mass (g); DW, Deficit watering (treatment); MAT, Mean average temperature; NW, Normal watering (treatment); $\sum L_{\text {root } \theta<0.5 \mathrm{~mm}}$ :TLA, Ratio of cumulated length of superfine roots per total leaf area $\left(\mathrm{cm} / \mathrm{cm}^{2}\right) ; P$ Diff- $B M_{\text {total }}$, Percent decrease of mean total individual biomass under deficit watering $(\%) ; p_{\mathrm{W}}$, Saturation vapour pressure $(\mathrm{kPa}) ; r H$, Relative air humidity $(\%)$; SRC, Short rotation coppice; $T$, Temperature $\left({ }^{\circ} \mathrm{C}\right) ; T L A$, Total leaf area $\left(\mathrm{cm}^{2}\right) ; V P D$, Saturation vapour pressure deficit $(\mathrm{kPa}) ; \theta_{\mathrm{V}}$, Volumetric soil moisture content (Vol.\%)

Supplementary Information The online version contains supplementary material available at https://doi.org/10.1007/s12155-021-10264-6. 
Acknowledgements We gratefully acknowledge the funding, the support by the BBI-JU for implementing the project D4EU (www. dendromass4europeeu), and the work of all our project partners. The lab work and greenhouse control were only possible with the great help of our TU Dresden staff members N. Opfermann, K. Schaeffer, J.-U. Polster, B. Reiche, J. Tippmann, I. Szut, A. Solger, J. Heinermann, L. Winkler, M. Krusche and of the graduation candidates M. Stracke, J.-E. Hahn. Many thanks are due to our colleagues K. Skibbe, A. Otto, A. Karge at the TU Dresden (Chair of Silviculture) for the general greenhouse maintenance. We thank Mr. Weitz, Mr. Stolz and Mr. Burmester (Lignovis GmbH, Germany) as well as Mr. Lukán and Mr. Sýkora for their kind assistance in Germany and the Slovak Republic.

Funding Open Access funding enabled and organized by Projekt DEAL. This project (Dendromass4Europe, D4EU) has received funding from the Bio-Based Industries Joint Undertaking under the European Union's Horizon 2020 Research and Innovation Programme under the grant agreement No. 745874. (https://www.bbi-europe.eu/projects/ dendromass4europe/)

\section{Declarations}

Conflict of Interest The authors declare no competing interests.

Open Access This article is licensed under a Creative Commons Attribution 4.0 International License, which permits use, sharing, adaptation, distribution and reproduction in any medium or format, as long as you give appropriate credit to the original author(s) and the source, provide a link to the Creative Commons licence, and indicate if changes were made. The images or other third party material in this article are included in the article's Creative Commons licence, unless indicated otherwise in a credit line to the material. If material is not included in the article's Creative Commons licence and your intended use is not permitted by statutory regulation or exceeds the permitted use, you will need to obtain permission directly from the copyright holder. To view a copy of this licence, visit http://creativecommons.org/licenses/by/4.0/.

\section{References}

1. Stanturf JA, van Oosten C (2013) Operational poplar and willow culture. In: Isebrands JG, Richardson J (eds) Poplars and Willows. Trees for Society and the Environment. Food and Agriculture Organization of the United Nations and CABI publishing, Wallingford, Boston, pp 200-257

2. Farmer RE (1996) The genecology of Populus. In: Stettler R, Bradshaw HD, Heilman PE, Hinckley TM (eds) Biology of Populus and its Implications for Management and Conservation. NRC Research Press, Ottawa, Canada, pp 33-55

3. Bonhomme L, Barbaroux C, Monclus R, Morabito D, Berthelot A, Villar M, Dreyer E, Brignolas F (2008) Genetic variation in productivity, leaf traits and carbon isotope discrimination in hybrid poplars cultivated on contrasting sites. Ann Forest Sci 65(5) art.no.503:501-509

4. Keller SR, Soolanayakanahally RY, Guy RD, Silim SN, Olson MS, Tiffin P (2011) Climate-driven local adaptation of ecophysiology and phenology in balsam poplar, Populus balsamifera L. (Salicaceae). Am J Bot 98(1):99-108. https://doi.org/10.3732/ajb. 1000317

5. Monclus R, Villar M, Barbaroux C, Bastien C, Fichot R, Delmotte FM, Delay D, Petit JM, Brechet C, Dreyer E, Brignolas F (2009) Productivity, water-use efficiency and tolerance to moderate water deficit correlate in 33 poplar genotypes from a Populus deltoides $\mathrm{x}$ Populus trichocarpa F-1 progeny. Tree Physiol 29(11):1329-1339

6. Guo XY, Zhang XS, Huang ZY (2010) Drought tolerance in three hybrid poplar clones submitted to different watering regimes. J Plant Ecol-Uk 3(2):79-87. https://doi.org/10.1093/Jpe/Rtq007

7. Monclus R, Dreyer E, Villar M, Delmotte FM, Delay D, Petit JM, Barbaroux C, Thiec D, Brechet C, Brignolas F (2006) Impact of drought on productivity and water use efficiency in 29 genotypes of Populus deltoides x Populus nigra. New Phytol 169(4):765-777

8. Dickmann DI, Isebrands JG (2001) Poplar clones: an introduction and caution. In: Dickmann DI, Isebrands JG, Eckenwalder JE, Richardson J (eds) Poplar Culture in North America. NRC Research Press, Ottawa, ON, Canada, pp 309-324

9. Zalesny RS, Riemenschneider DE, Hall RB (2005) Early rooting of dormant hardwood cuttings of Populus: analysis of quantitative genetics and genotype $\mathrm{x}$ environment interactions. Can J For Res 35(4):918-929

10. Zalesny RS, Wiese AH (2006) Date of shoot collection, genotype, and original shoot position affect early rooting of dormant hardwood cuttings of Populus. Silvae Genet 55(4-5):169-182. https:// doi.org/10.1515/sg-2006-0024

11. Rogers ER, Zalesny RS, Hallett RA, Headlee WL, Wiese AH (2019) Relationships among root-shoot ratio, early growth, and health of hybrid poplar and willow clones grown in different landfill soils. Forests 10(1):18. https://doi.org/10.3390/f10010049

12. Wullschleger S, Yin TM, DiFazio SP, Tschaplinski TJ, Gunter LE, Davis MF, Tuskan GA (2005) Phenotypic variation in growth and biomass distribution for two advanced-generation pedigrees of hybrid poplar. Canadian Journal of Forest Research - Revue Canadienne de Recherche Forestière 35(8):1779-1789

13. Krabel D, Meyer M, Solger A, Müller R, Carvalho P, Foulkes J (2015) Early root and aboveground biomass development of hybrid poplars (Populus spp.) under drought conditions. Can J For Res 45(10):1289-1298. https://doi.org/10.1139/cjfr-2015-0126

14. Al Afas N, Marron N, Zavalloni C, Ceulemans R (2008) Growth and production of a short-rotation coppice culture of poplar-IV: fine root characteristics of five poplar clones. Biomass Bioenergy 32(6): 494-502

15. Brunner I, Herzog C, Dawes MA, Arend M, Sperisen C (2015) How tree roots respond to drought. Front Plant Sci 6(547). https:// doi.org/10.3389/fpls.2015.00547

16. Marron N, Brignolas F (2013) Water deficit. In: Isebrands JG, Richardson J (eds) Poplars and willows. Trees for Society and the Environment. FAO, CABI publishing, Wallingford, Boston, pp 338-405

17. Stettler RF, Bradshaw HD, Heilman PE, Hinckley TM (1996) Biology of Populus and its implications for management and conservation. NRC Research Press, Ottawa, Ontario

18. Ledo A, Paul KI, Burslem DFRP, Ewel JJ, Barton C, Battaglia M, Brooksbank K, Carter J, Eid TH, England JR, Fitzgerald A, Jonson J, Mencuccini M, Montagu KD, Montero G, Mugasha WA, Pinkard E, Roxburgh S, Ryan CM, Ruiz-Peinado R, Sochacki S, Specht A, Wildy D, Wirth C, Zerihun A, Chave J (2018) Tree size and climatic water deficit control root to shoot ratio in individual trees globally. New Phytol 217(1):8-11. https://doi.org/10.1111/ nph.14863

19. Reich PB, Luo Y, Bradford JB, Poorter H, Perry CH, Oleksyn J (2014) Temperature drives global patterns in forest biomass distribution in leaves, stems, and roots. Proc Natl Acad Sci 111(38): 13721-13726. https://doi.org/10.1073/pnas.1216053111

20. Ibrahim L, Proe MF, Cameron AD (1997) Main effects of nitrogen supply and drought stress upon whole-plant carbon allocation in poplar. Can J For Res 27(9):1413-1419. https://doi.org/10.1139/ $\times 97-080$ 
21. Comas LH, Becker SR, Cruz VMV, Byrne PF, Dierig DA (2013) Root traits contributing to plant productivity under drought. Front Plant Sci 4:442. https://doi.org/10.3389/fpls.2013.00442

22. Broeckx LS, Verlinden MS, Ceulemans R (2012) Establishment and two-year growth of a bio-energy plantation with fast-growing Populus trees in Flanders (Belgium): effects of genotype and former land use. Biomass Bioenergy 42:151-163. https://doi.org/10.1016/ j.biombioe.2012.03.005

23. Steenackers M, De Clercq W, Schamp K (2018) De INBO variëteiten van populier, een aanwinst voor de Europese populierenteelt [in Dutch]. Silva Belgica No.4/2018:40-47

24. BLE (2019) Die Pappel - Klone, Klonmischungen und Familieneltern - Stand 10.07.2019 [Poplar - Clones, clone mixtures, familiy parents, as of 2019-07-10. In German]. Federal Office for Agriculture and Food, Referat 331 - Registerstelle für geprüftes Vermehrungsut der Pappel, Deichmanns Aue 29, 53179 Bonn, Germany

25. Weisgerber H (1983) Wuchsverhalten und Anbaumöglichkeiten einiger neu zum Handel zugelassener Balsampappeln und Aspen. Die Holzzucht 37(Juli):2-10

26. Grotehusmann H, Janssen A, Haikali A, Hartmann K-U, Hüller W, Karopka M, Schildbach M, Schirmer R, Schuppelius T, Töpfner K (2015) Pappelsortenprüfungen im Projekt FastWOOD [Poplar variety test in the project FastWOOD]. Forstarchiv 86(3):67-79

27. Dickmann DI, Kuzovkina YA (2013) Poplars and willows of the world, with emphasis on sylviculturally important species. In: Isebrands JG, Richardson J (eds) Poplars and Willows. Trees for Society and the Environment. Food and Agriculture Organization of the United Nations and CABI publishing, Wallingford, Boston, pp 8-91

28. Eckenwalder JE (2001) Descriptions of clonal characteristics. In: Dickmann DI, Isebrands JG, Eckenwalder JE, Richardson J (eds) Poplar Culture in North America. NRC Research Press, Ottawa, ON, Canada, pp 331-382

29. IPC (2016) Checklist for Cultivars of Populus L. (poplar); document available online http://www.fao.org/forestry/449820186a843525e482bc519cb1cfe5bcd12d.pdf 2018-01-16. International Populus Cultivar Registration Authority at the International Poplar Commission, IPC, at the FAO, Rome, Italy

30. Stanton BJ, Serapiglia MJ, Smart LB (2013) The domestication and conservation of Populus and Salix genetic resources. In: Isebrands JG, Richardson J (eds) Poplars and Willows. Trees for Society and the Environment. Food and Agriculture Organization of the United Nations and CABI publishing, Wallingford, Boston, pp 124-199

31. Tschaplinski TJ, Tuskan GA, Gebre GM, Todd DE (1998) Drought resistance of two hybrid Populus clones grown in a large-scale plantation. Tree Physiol 18(10):653-658

32. Joachim H-F (1953) Untersuchungen über die Wurzelausbildung der Pappel und die Standortansprüche von Pappelsorten, vol Band VII. Wissenschaftliche Abhandlungen. Wissenschaftliche Abhandlungen Deutsche der Akademie der Landwirtschaftswissenschaften zu Berlin. Band VII., Berlin
33. Adonsou KE, DesRochers A, Tremblay F (2016) Physiological integration of connected balsam poplar ramets. Tree Physiol 36(7):797-806

34. Adonsou KE, DesRochers A, Tremblay F, Thomas BR, Isabel N (2016) The clonal root system of balsam poplar in upland sites of Quebec and Alberta. Ecol Evol 6(19):6846-6854

35. Pregitzer KS, Dickmann DI, Hendrick R, Nguyen PV (1990) Whole-tree carbon and nitrogen partitioning in young hybrid poplars. Tree Physiol 7(1-4):79-93. https://doi.org/10.1093/treephys/7. $1-2-3-4.79$

36. BLE (2012) Die Pappel - Klone, Klonmischungen und Familieneltern (BLE). Federal Office for Agriculture and Food, Referat 324, Deichmanns Aue 29, 53179 Bonn, Germany

37. TU Dresden (2019) Chair of Meteorology, Eichelmann, Uwe [ed.], https://tu-dresden.de/bu/umwelt/hydro/ihm/meteorologie/ forschung/mess-und-versuchsstationen/grillenburg-klimastation? set language $=e n$, accessed 2020-04-20.

38. Eziz A, Yan ZB, Tian D, Han WX, Tang ZY, Fang JY (2017) Drought effect on plant biomass allocation: a meta-analysis. Ecol Evol 7(24):11002-11010

39. Poorter H, Niklas KJ, Reich PB, Oleksyn J, Poot P, Mommer L (2012) Biomass allocation to leaves, stems and roots: meta-analyses of interspecific variation and environmental control. New Phytol 193(1):30-50. https://doi.org/10.1111/j.1469-8137.2011.03952.x

40. Monclus R, Dreyer E, Delmotte FM, Villar M, Delay D, Boudouresque E, Petit JM, Marron N, Brechet C, Brignolas F (2005) Productivity, leaf traits and carbon isotope discrimination in 29 Populus deltoides x P. nigra clones. New Phytol 167(1):5362

41. Marron N, Delay D, Petit JM, Dreyer E, Kahlem G, Delmotte FM, Brignolas F (2002) Physiological traits of two Populus x euramericana clones, Luisa Avanzo and Dorskamp, during a water stress and re-watering cycle. Tree Physiol 22(12):849-858

42. Rasheed F, Dreyer E, Richard B, Brignolas F, Brendel O, le Thiec D (2015) Vapour pressure deficit during growth has little impact on genotypic differences of transpiration efficiency at leaf and wholeplant level: an example from Populus nigra L. Plant Cell Environ 38(4):670-684. https://doi.org/10.1111/pce.12423

43. Larcheveque M, Maurel M, DesRochers A, Larocque GR (2011) How does drought tolerance compare between two improved hybrids of balsam poplar and an unimproved native species? Tree Physiol 31(3):240-249. https://doi.org/10.1093/treephys/tpr011

44. Lösch R (2001) Wasserhaushalt der Pflanzen, 1st edn. Quelle \& Meyer, UTB, Wiebelsheim, Germany

45. IUSS Working Group WRB (2015) World reference base for soil resources 2014, update 2015, International soil classification system for naming soils and creating legends for soil maps. World Soil Resources Reports No. 106. FAO, Rome, Italy

Publisher's Note Springer Nature remains neutral with regard to jurisdictional claims in published maps and institutional affiliations. 